\title{
Economic implications of climate change impacts on human health through undernourishment
}

\author{
Tomoko Hasegawa $^{1} \cdot$ Shinichiro Fujimori $^{1}$ • \\ Kiyoshi Takahashi $^{1}$ - Tokuta Yokohata ${ }^{2}$. \\ Toshihiko Masui ${ }^{1}$
}

Received: 19 May 2015 / Accepted: 12 January 2016 / Published online: 29 January 2016

C The Author(s) 2016. This article is published with open access at Springerlink.com

\begin{abstract}
This study quantified the impacts of climate change on human health through undernourishment using two economic measures. First, changes in morbidity and mortality due to nine diseases caused by being underweight as a child were analyzed using a Computable General Equilibrium (CGE) model with changes in the labor force, population, and demands for healthcare taken into consideration. Second, changes in mortality were taken from the CGE simulation and assessed economically by the value of lives lost and willingness to pay to reduce the risk. Model uncertainties in future crop yields and climate conditions were considered using future projections from six global crop models and five global climate models. We found that the economic valuation of healthy lives lost due to undernourishment under climate change was equivalent to $-0.4 \%$ to $0.0 \%$ of global gross domestic product (GDP) and was regionally heterogeneous, ranging from $-4.0 \%$ to $0.0 \%$ of regional GDP in 2100. In contrast, the actual economic losses associated with the effects of additional health expenditure and the decrease in the labor force due to undernourishment resulting from climate change corresponded to a $-0.1 \%$ to $0.0 \%$ change in GDP and a $-0.2 \%$ to $0.0 \%$ change in household consumption, respectively, at the global level.
\end{abstract}

Electronic supplementary material The online version of this article (doi:10.1007/s10584-016-1606-4) contains supplementary material, which is available to authorized users.

Tomoko Hasegawa

hasegawa.tomoko@nies.go.jp

1 Center for Social \& Environmental Systems Research, National Institute for Environmental Studies, 16-2 Onogawa, Tsukuba, Ibaraki 305-8506, Japan

2 Center for Global Environmental Research, National Institute for Environmental Studies, 16-2

Onogawa, Tsukuba, Ibaraki 305-8506, Japan 


\section{Introduction}

A number of studies have economically evaluated the effects of climate change on human health (Bosello et al. 2006; Ciscar et al. 2011; Smith et al. 2014; Tol 2013; Watkiss and Hunt 2012). The impact on human health due to climate change includes death and disease by extreme heat and cold (Ciscar et al. 2011; Tol 2013; Watkiss and Hunt 2012), low labor force productivity and associated medical services (Bosello et al. 2006), mortality due to natural disasters, infectious diseases via food and water, and death or disease due to undernourishment. With regard to undernourishment, climate change has a negative impact on crop production (Rosenzweig and Parry 1994), which is expected to increase the risk of hunger and undernourishment (Hasegawa et al. 2014; Nelson et al. 2014). Being underweight as a child is a major risk factor of disease and death in low-income countries, and has led to serious diseases such as diarrhea and malaria (Ezzati et al. 2004). In addition, undernourishment due to climate change has negative health effects in underweight children (Ishida et al. 2014; Lloyd et al. 2011) and in the worst case leads to the death of children (Lloyd et al. 2014).

To analyze the responses to climate change and the actions taken in the future, previous studies have performed cost-benefit analysis using dynamic optimization models (Cline 1992; Fankhauser 1995; Nordhaus 1991; Tol 2013). The optimal level was set as the maximization of utility, which was expressed as a function of consumption. The consumption is defined as GDP minus the sum total of the costs of mitigation and adaptation to climate change and the residual climate damage that might occur. These studies also evaluated the impact on sectors that are not treated in the market (e.g., human death due to extreme heat and cold, loss of comfort, migration associated with natural disasters) as shown in Tol (1996). Some studies have suggested that sectors that are not treated in the market experience greater damage than sectors treated in the market, for example in OECD countries. In recent years, lives lost due to extreme heat and cold have been economically evaluated (Watkiss and Hunt 2012).

Many studies have focused on the impacts of climate change on health, undernourishment, and death or diseases, but have not assessed the economic implications of death or diseases caused by undernourishment due to climate change. By considering the negative effects on health as well as the valuations of the lives lost from undernourishment, a better economic assessment of the impact of climate change on human health can be achieved.

This study quantified the impact of future climate change on human health by considering nine diseases (diarrheal diseases, pertussis, measles, tetanus, meningitis, malaria, lower respiratory infections, birth asphyxia and birth trauma, and protein-energy malnutrition), which are caused by being underweight as a child. Furthermore, this study quantified the economic value of lives lost as an economic indicator for measuring the impact on health.

\section{Methods}

\subsection{Modeling framework}

We used the modeling framework shown in Fig. 1. Future grid-based crop yield data were aggregated for each region, and then input into the economic model (The Asia-Pacific Integrated Model/Computable General Equilibrium: AIM/CGE). The CGE model outputs several indicators to measure the impact on undernourishment and human health. We used the same framework as in previous studies (Hasegawa et al. 2015a; Ishida et al. 2014), in 
which the model was used to calculate food calorie intake, population at risk of hunger and disability-adjusted life years (DALY). Ishida et al. (2014) estimated the DALY for 2050, whereas this study expanded the analysis to the end of this century. We also improved the model to calculate more indicators: GDP and consumption loss caused by health impacts due to climate change, the associated medical expenditure, and the economic value of lives lost. Moreover, we revised Ishida et al. (2014), by assuming reductions in unequal food distributions with GDP, which significantly impacts on future undernourishment (Hasegawa et al. 2015b) (see chapter S3.2 in the supplementary material). To quantify the uncertainty in future projections of crop yields, climatic conditions, and socioeconomic conditions, we used a data for future changes in crop yield projected by multiple global crop models and global climate models (Rosenzweig et al. 2014) and assumed multiple socioeconomic conditions.

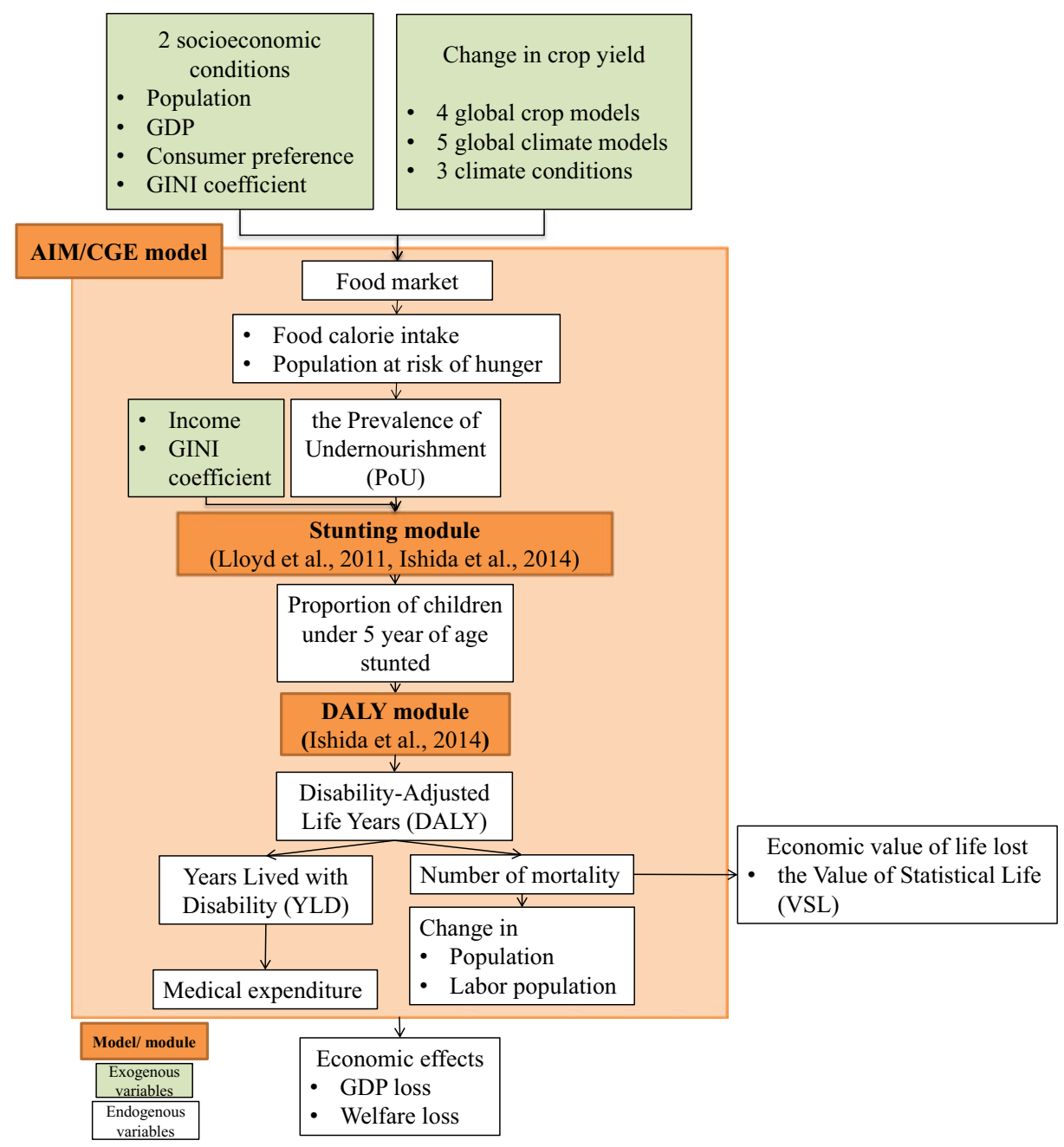

Fig. 1 Modeling framework 


\subsection{The AIM/CGE model and changes from the earlier version}

\subsubsection{The AIM/CGE model}

The AIM/CGE model builds on the work by Fujimori et al. (2012, 2014), and recently several climate change studies used the model (Fujimori et al. 2014; Hasegawa et al. 2014). Supply, demand, trade, and investment are described as individual behavioral functions that respond to changes in the price of production factors and commodities, as well as changes in technology. The functions also respond to preference parameters on the basis of the assumed population, GDP, and consumer preferences. The model contains 17 regions (Table S1) and 42 industrial classifications including 10 agricultural sectors (Table S2). The healthcare sector was aggregated with other service sectors to produce one service sector in the model. See Chapter S1 of the supplementary material for more detail.

\subsubsection{Feedback of medical expenditure to household consumption}

The changes in medical expenditure was calculated and fed back to the consumption expenditure. To calculate additional medical expenditure, first, the Years Lived with Disability (YLD) were calculated from the DALY by assuming the current ratio of the YLD to the future DALY. The current ratio of YLD to DALY was determined from the DALY and YLD by disease type in seven regions of the world in 2004 (WHO 2014a). Then, additional medical expenditure resulting from health damage was calculated by multiplying the YLD and annual medical expenditure per person (See section 2.4.3 for more details). Households were assumed to bear the medical expenditures, which were expressed by subtracting the medical expenditure from the total consumption expenditure of households.

\subsubsection{Feedback of mortality to population and the labor force}

The change in the number of deaths due to climate change was fed back to the population and the labor force. First, the mortality due to disease was calculated from the DALY by assuming the current ratio of the number of mortality to the future DALY. Then, the additional number of deaths was deducted from the future potential population and labor force, which were assumed to be the population and the labor force in the case of no climate change (NoCC). Therefore, on the basis of the potential population, the cumulative number of additional deaths of children under 5 years of age due to climate change from the base year to a year was subtracted from the next year's population. The additional childhood mortality changed the population over the period of their life expectancy (WHO 2014b) from the year of death. Changes in the labor population were similarly expressed, and the labor population changed 15 to 64 years after their deaths. There was a strong assumption that the labor force changed in proportion to the change in the labor population. This feedback was performed recursively for each year, with the total number of deaths passed onto the following year. Here, the number of people that would have been born if their mother did not die was not considered.

\subsection{Economic valuation of lost life}

Various attempts have been made to evaluate the value of a life. All lives should have an equal value; however, rich people are able to place an overall higher value on their lives (Cropper 
et al. 2011; OECD 2012; Pearce 1978). In addition, the willingness to pay (WTP) for death avoidance may differ by country and cause of death. The value of statistical life (VSL) is a summary measurement of the WTP for a mortality risk (OECD 2012). The VSL is defined as the marginal value of a reduction in the risk of dying and is used as a key input in the calculation of the costs and benefits of policies that save lives. OECD (2012) developed an approach to estimate the VSL, where the VSL is derived using an income adjustment. This study used the approach. We applied a reference value of the VSL to other regions using an income elasticity of 0.8 (OECD 2012) (Eq. 1). Then, the sum of the VSL was derived by multiplying the VSL and the level of mortality in each region (Eq. 2). As the reference value, the value of the health risk observed in China, 2005 was selected because the Chinese survey had the largest number (110) of observations among the surveys used in OECD (2012) and we judged it to be more suitable for the issues investigated in this study than the values for developed countries. Although the OCED approach considers not only per-capita income but also other explanatory factors, factors other than per-capita income were not considered in the study because more detailed information would be required and this was not available. To express the uncertainty in the assessment of the value of a life is considered possible. High and low values of the VSL were estimated by assuming a range of the reference value of the VSL and a standard deviation of the income elasticity.

$$
\begin{gathered}
V S L_{t, r}=V S L r e f \cdot\left(\frac{G D P C A P_{t, r}}{\text { GDPCAPref }}\right)^{\text {incomeelas }} \\
T V S L_{t, r, d}=V S L_{t, r} \cdot D E A T H_{t, r, d}
\end{gathered}
$$

where,

$\begin{array}{ll}V_{\text {VSL }}, r, d & \text { Value of Statistical Life (VSL) caused by disease } d \text {, in region } r \text { and year } t \\ \text { VSLYref } & \text { a reference value of the VSLY } \\ \text { GDPCAP } & \text { GDP per capita in region } r \text { and year } t \\ \text { GDPCAPref } & \text { GDP per capita for a reference region and year } \\ \text { TVSL }_{t, r} & \text { The sum of the VSL in region } r \text { and year } t, \\ \text { Incomeelas }_{\text {DEATH }} & \text { income elasticity (0.8) } \\ \text { DEAT, }_{t, d} & \text { DEATH caused by disease d, in region } r \text { and year } t .\end{array}$

\subsection{Scenarios and data used in this study}

\subsubsection{Scenarios}

To quantify the uncertainty in climate and socioeconomic conditions we prepared four scenarios combining two socioeconomic conditions and three climatic conditions including a reference case that assumed current climatic conditions would prevail in the future (i.e., NoCC) as shown in Table 1. As the socioeconomic conditions we used population and GDP values based on the intermediate ("middle-of-the-road", SSP2) and pessimistic ("fragmentation", SSP3) scenarios of the Shared Socioeconomic Pathways (SSPs) (IIASA 2012) (Figure S4) to investigate the relatively negative climate impacts. Other socioeconomic conditions were based on Hasegawa et al. (2015b). The Representative Concentration 
Pathways (RCPs), RCP2.6 (van Vuuren et al. 2011) and RCP8.5 (Riahi et al. 2011), were used as the climate conditions. The RCP2.6 is the pathway where climate change is most mitigated; whereas in RCP8.5, it progresses the most. Furthermore, we simulated cases with and without the feedback of the impacts of undernourishment shown in section 2.2.2 and 2.2.3, and extracted the effect of undernourishment by differentiating the two scenarios. This is because the change in GDP and household consumption estimated in the present study is a consequence of both impacts on crop yield and on the changes in the population, labor force, and medical expenditure due to undernourishment. The impacts of crop yield changes are shown in the supplementary material (e.g. Figure S6). The scenarios were run for the period of $2005-2100$.

\subsubsection{Crop yields}

Future changes in crop yields are mainly driven by technological developments and climate change impacts. To reflect the technological developments, we used crop yields in the case of NoCC, assuming present climate conditions for the future. However, these yields do not reflect the impacts of climate change. To consider those impacts, change in crop yield due to climate change was calculated by multiplying a ratio of the change in the yield with the yield in the NoCC case (See Hasegawa et al. (2014) for the treatment of yield changes).

We used the yield change in the NoCC case developed by Hasegawa et al. (2015b) on the basis of the yield data used in the agricultural modeling intercomparison and improvement project (AgMIP) (Nelson et al. 2014). The rate of change in crop yields due to climate change was calculated from data provided by the Inter-Sectoral Impact Model Intercomparison Project (ISIMIP) (Rosenzweig et al. 2014). We selected the global crop models and global climate models shown in Table S6, which covered a wide range of crops under both RCPs. Crop types are classified as shown in Table S7. As with AgMIP, $\mathrm{CO}_{2}$ fertilization was not considered in this study (Nelson et al. 2014), although it has been reported that the $\mathrm{CO}_{2}$ fertilization effects on crop yield are large (Masutomi et al. 2009).

Table 1 Scenarios used in this study

\begin{tabular}{|c|c|c|c|c|}
\hline Scenario & $\begin{array}{l}\text { Socioeconomic } \\
\text { conditions }\end{array}$ & Climate conditions & $\begin{array}{l}\text { Feedback of the impacts } \\
\text { of undernourishment }\end{array}$ & $\begin{array}{l}\text { Impacts to } \\
\text { be analyzed }\end{array}$ \\
\hline \multirow[t]{2}{*}{ Reference } & SSP2 & NoCC & \multirow[t]{2}{*}{-} & \multirow[t]{2}{*}{-} \\
\hline & SSP3 & NoCC & & \\
\hline \multirow[t]{2}{*}{ Mitigation } & SSP2 & RCP2.6 & \multirow[t]{2}{*}{ on } & Changes in \\
\hline & SSP3 & $\mathrm{RCP} 2.6$ & & - crop yields \\
\hline \multirow[t]{3}{*}{$\mathrm{BaU}$} & $\mathrm{SSP} 2$ & $\mathrm{RCP} 8.5$ & & - medical expenditure \\
\hline & \multirow[t]{2}{*}{ SSP3 } & \multirow[t]{2}{*}{ RCP8.5 } & & • population \\
\hline & & & & - labour force \\
\hline \multicolumn{5}{|l|}{ Subscenario } \\
\hline \multirow[t]{2}{*}{ Mitigation } & SSP2 & $\mathrm{RCP} 2.6$ & \multirow[t]{4}{*}{ off } & \multirow[t]{4}{*}{ Changes in crop yields } \\
\hline & SSP3 & $\mathrm{RCP} 2.6$ & & \\
\hline \multirow[t]{2}{*}{$\mathrm{BaU}$} & $\mathrm{SSP} 2$ & RCP8.5 & & \\
\hline & SSP3 & RCP8.5 & & \\
\hline
\end{tabular}

Note: $N o C C$ No climate change assuming present climate conditions for the future 


\subsubsection{Medical expenditure}

Medical expenditure resulting from health damage was calculated by multiplying the YLD and medical expenditure per YLD by disease type (Eq. 3). The medical expenditure per YLD by disease was calculated as a sum of expenditure per year for inpatients and outpatients (Eq. 4). The expenditure per year for inpatient and outpatient was calculated by multiplying i) medical expenditure per day by disease and patient type $(M E D)$, ii) ratios of inpatient and outpatient days per year by disease (RDAYs), and 365 days. For the $M E D$, we applied values of China (National Health and Family Planning Commission of the People's Republic of China 2015 ) to other mid- or low-income regions according to the GDP per capita (Eq. 5). This is based on the assumption that medical expenditure is determined mostly by wages and the level of medical technology available, which increases with economic level. The values for China were used as a reference because the daily inpatient and outpatient expenditure by disease is available, and because it is more suitable for the issues investigated in this study than are values for developed countries. The RDAYs were calculated as Eq. 6 using values of Japan (Ministry of Health, Labour and Welfare of Japan (2015) and applied for all regions because there was not enough data available for China and other similar countries. For both of $M E D$ and $R D A Y_{s}$, in cases where data for the same diseases were not available, mean values within the same category of disease were applied (Table S8 and Table S9). Although we used the common values for the $R D A Y s$, we considered regional heterogeneity in the annual medical expenditure by differentiating the $M E D$ among regions according to the economic levels.

$$
\begin{gathered}
M E_{t, r, d}=Y L D_{t, r, d} \cdot M E Y_{t, r, d} \\
M E Y_{t, r, d}=\sum_{p}\left(M E D_{t, r, d, p} \cdot R D A Y s_{d, p} \cdot 365\right) \\
M E D_{t, r, d, p}=M E D r e f_{d, p} \cdot\left(\frac{G D P C A P_{t, r}}{G D P C A P r e f}\right) \\
\operatorname{RDAY}_{d, p}=\frac{D A Y s_{d, p}}{D A Y s_{d,{ }^{\prime} \text { 'inpatient' }}+D A Y s_{d,,^{\prime} \text { outpatient' }}}
\end{gathered}
$$

where,

$t$ : year, $r$ : region, $d$ : disease, $p$ : patient type,

$D A Y_{d, p} \quad$ Days of patient type $p$ per year for disease $d$ in a reference country,

$G D P C A P_{t, r} \quad$ GDP per capita for year $t$, region $r$,

GDPCAPref GDP per capita for a reference country,

$M E_{t, r, d} \quad$ medical expenditure for year $t$, region $r$, disease $d$,

$M E D_{t, r, d, p} \quad$ medical expenditure per day for year $t$, region $r$, disease $d$, patient type $p$,

MEDref $f_{d, p} \quad$ medical expenditure per day for disease $d$, patient type $p$ for a reference country,

$M E Y_{t, r, d} \quad$ medical expenditure per YLD for year $t$, region $r$, disease $d$,

$R D A Y_{d, p} \quad$ ratios of days of patient type $p$ per year for disease $d$,

$Y L D_{t, r, d} \quad$ the YLD for year $t$, region $r$, disease $d$. 


\section{Results}

\subsection{Health effects of undernourishment}

Figure 2 compares representative indicators of food and undernourishment (global mean food calorie intake, global population at risk of hunger, DALY, and DALY per 1000 persons) between different socioeconomic and climate conditions from the basis of the case of NoCC. Under the strong climate change in RCP8.5, negative effects such as an increase in the undernourished population and DALY, and decreases in the food intake were very likely regardless of the socioeconomic conditions. In contrast, these effects in RCP2.6 were small.

Several observations could be made from the uncertainty ranges of global crop models and global climate models. First, future health damage through undernourishment was more dependent on socioeconomic conditions than climate conditions throughout this century, because the DALY ranges overlapped across the latter, but not the former. This is because food intake and risk of hunger varies more across different socioeconomic conditions (e.g., population and income) rather than climate conditions (Hasegawa et al. 2014), and as a result the same was true for the DALY, which was derived from the above variables. Second, the ranges in RCP8.5 were much wider than those in RCP2.6, because for several regions where large effects were expected, the uncertainty range was larger in RCP8.5 than RCP2.6 depending on the uncertainty of yield changes and degree of crop consumption. See Figure S7 of the supplementary material for regional yield changes under different climate conditions, with uncertainty
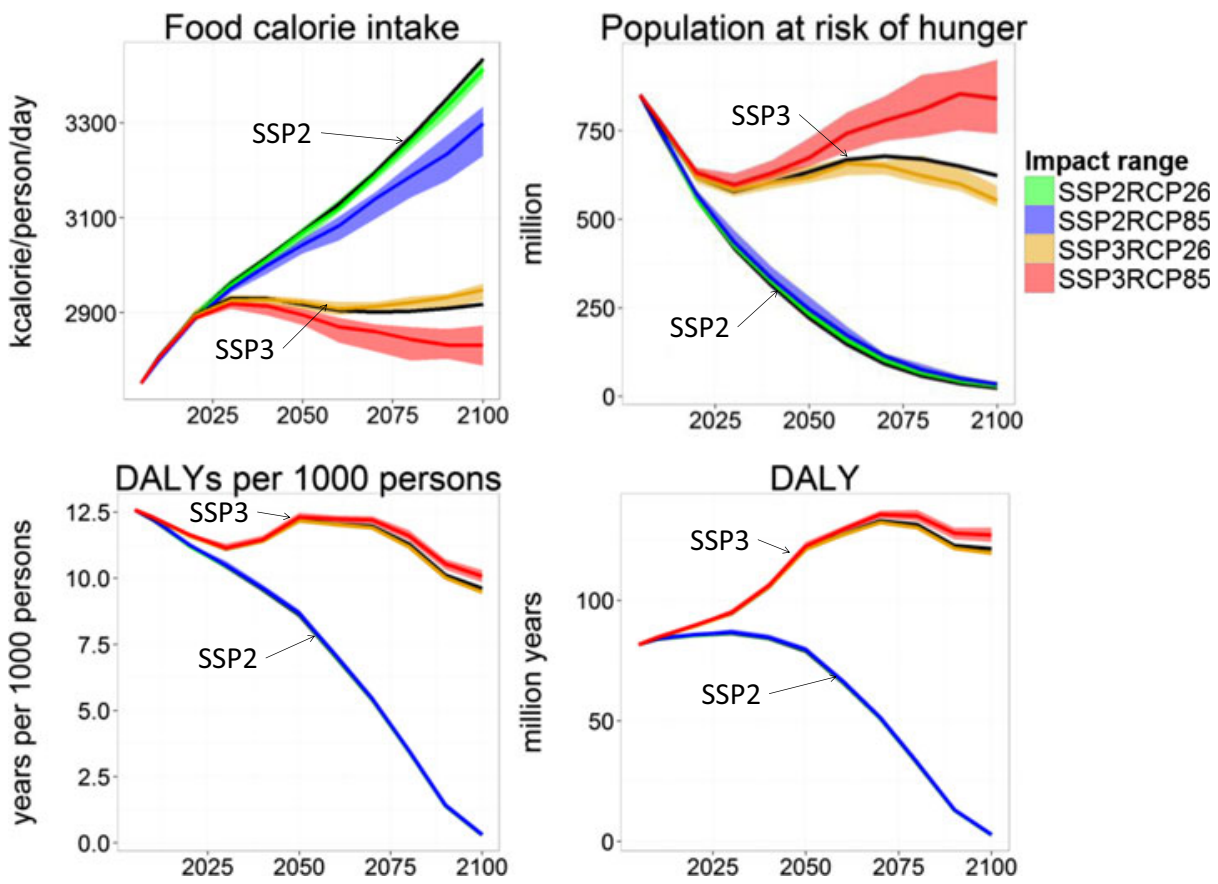

Fig. 2 The impact of climate change on mean food calorie intake, population at risk of hunger, DALY per 1000 persons, and DALY under different socioeconomic scenarios (It should be noted that the scenarios developed in this article differ from the final products of the SSPs, which are forthcoming. Please see the forthcoming special issues for the final scenarios of the SSPs.). The black line shows the level with no climate change. The ranges show the uncertainty of global crop models and global climate models from the highest to the lowest values 
ranges across global crop models and global climate models. Third, the uncertainty ranges in SSP3 were much wider than those in SSP2 in the latter half of this century. This was not surprising because the food intake increased and undernourishment was eliminated in SSP2 during the study period. Finally, the DALY ranges were narrower than those in the PoU because the DALY were not only determined by the PoU, but also by other factors such as income and the Gini coefficient (see section S4.1 of the SI). The contribution of the PoU became weak and the ranges become narrower than those of the PoU because uncertainty in the Gini coefficient, which drives the PoU, was not considered (See section S4.1 of the SI for more detail).

\subsection{Regional impacts}

Figure 3 shows the regional climate change impacts on average food consumption, PoU, and the DALY per 1000 persons compared with the scenario without climate change for the pessimistic scenario (SSP3-RCP8.5). The magnitude and the uncertainty of these effects were heterogeneous across the regions. For example, the magnitude and the uncertainty of these effects in the PoU and DALY were large in India and the rest of Asia. Food intake was relatively low for these regions, and therefore the PoU responds strongly to changes in food intake. A small decrease in food intake caused a large increase in PoU. Because the yield changes in wheat, which is largely consumed in these regions, are large, the magnitude of the impacts is large. Moreover, in these regions, the uncertainty range in food intake is relatively large because of the large uncertainty of yield changes for wheat (See Figure S7 in the supplementary material for regional yield changes.).

\subsection{Economic impact of the health burden due to undernourishment caused by climate change}

The regional impact on the economy of the health burden of undernourishment caused by climate change varies between regions, with a -0.9 to $+0.1 \%$ change for GDP and a -1.6 to $+0.1 \%$ change for household consumption for the largest impact case in 2100 . The regional positive impact is caused by increase in crop yields due to climate change, leading increase in food intake and decrease in health damage compared to the scenario without climate change. The global average impact was -0.1 to $0.0 \%$ and -0.2 to $0.0 \%$ for GDP and household consumption, respectively (Figure S5). This was much smaller than the economic impact of the
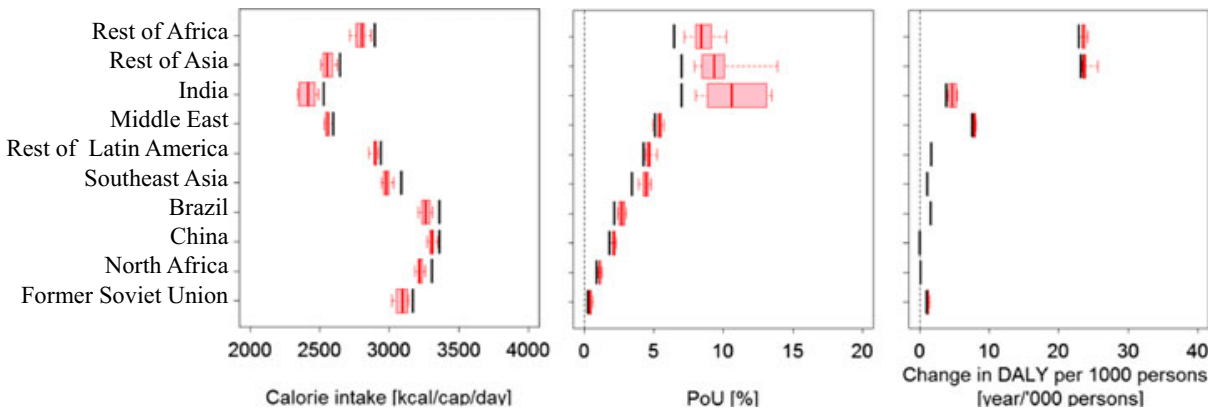

Fig. 3 The regional climate change impact on the mean food calorie intake, the prevalence of undernourishment (PoU), and the disability-adjusted life years (DALY) per 1000 persons under the pessimistic scenario (SSP3RCP8.5), in which climate change progressed the most by 2100. The black line shows the level with no climate change. Boxplots show the uncertainty ranges of global crop models and global climate models. Boxes indicate $25 \%$ values and whiskers indicate the maximum and minimum values 
changes to crop yields (Figure S6), because the effects of medical expenditure and the labor population were relatively small. There are several reasons for this. First, healthcare costs in low-income areas, where undernourishment is common, are relatively low. Second, the proportion of healthy lives lost due to disease in the DALY is small, with the majority of people suffering from disease dying prematurely. Premature death does not incur medical expenditure. Third, there is a time lag of more than 15 years until child mortality affects the labor population. Therefore, only the additional deaths within the past 15 years have an effect.

\subsection{Economic value of lives lost due to undernourishment caused by climate change}

Figure 4 shows the economic value of lives lost due to climate change relative to GDP at the (a) the global level and (b) the regional level, estimated by assuming different levels of life value for the most pessimistic scenario of SSP3-RCP8.5. At the global level, the economic value of lives lost due to climate change is equivalent to $-0.4 \%$ to $0.0 \%$ of GDP in 2100 . The evaluation based on the high level of life value ranges $-0.4 \%$ to $-0.15 \%$ of GDP, whereas the evaluation using the low level ranges $-0.05 \%$ to $0.0 \%$ of GDP. The range in the regional figure indicated an uncertainty that was not only due to global crop and climate models, but also to life values. The effects in South Asia and India were large, and were equivalent to a maximum of $-4.0 \%$ of GDP in South Asia. This is much larger compared to GDP loss due to medical expenditure and labor population reduction shown above. The impacts on the Rest of Asia are expected to be larger than those on Africa, although intuitively the situation might be expected to be different. However, this shows only the changes in the value of life lost due to climate change, not the absolute value of life lost. There are several reasons for the large impacts in India and South Asia. There is expected to be a large negative impact on the yield of wheat and other crops that are consumed in large amounts in the Rest of Asia. Also, land that is suitable for agriculture and for cropland expansion is limited in these regions. In contrast, there is not a large negative impact on the yield of maize or other coarse grains that are consumed in large amounts in Africa. In addition, the characteristics of the model used in the study, where it does not assume a large change in dietary culture and food trade in the future, might contribute to the results.

a) World

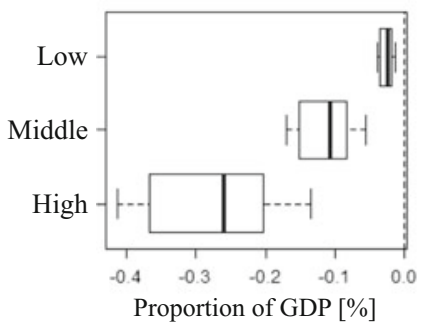

b) By region

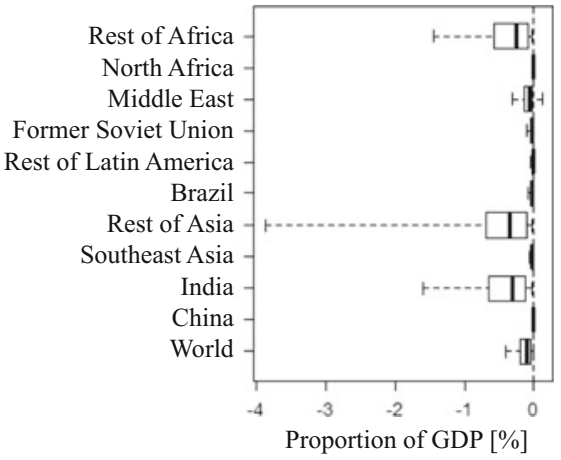

Fig. 4 Economic value (\%) of life lost due to climate change relative to the gross domestic product (GDP) in the case without climate change $\mathbf{a}$ at the global level and $\mathbf{b}$ in middle and low-income regions, estimated by different life values in the pessimistic scenario (SSP3-RCP8.5) where climate change has progressed the most in 2100. A negative value indicates a loss. Boxplots show the uncertainty ranges of global crop and climate models (a) and global crop and climate models and life valuation methods (b). Boxes indicate the $25 \%$ value and whiskers indicate the maximum and minimum values 


\section{Discussion and conclusions}

The present study economically assessed the health burden due to undernourishment caused by climate change. Furthermore, as an economic indicator to measure the extent of the health burden, the economic value of lost lives was assessed. We found that the economic valuation of a healthy life lost due to undernourishment under climate change was much larger than the effects of additional health expenditure and the decrease in the labor force due to undernourishment resulting from climate change. The effects of the former were equivalent to $-0.4 \%$ to $0.0 \%$ of global GDP and $-4.0 \%$ to $0.0 \%$ of regional GDP in 2100 . In contrast, the effects of the latter corresponded to a $-0.1 \%$ to $0.0 \%$ change in GDP and $-0.2 \%$ to $0.0 \%$ changes for consumption at the global level.

This study is the first attempt to assess the economic value of lives lost due to undernourishment. In addition to previous studies (Cline 1992; Fankhauser 1995; Nordhaus 1991; Tol 2013), we showed that the sectors not treated in the market are expected to receive more damage than those treated in the market. This suggests the possibility that impacts were underestimated in studies targeting only the sectors treated in the market. We also focused on the impacts of undernourishment not considered in previous studies. Our methodology could be applied to other impact assessments of the risk of hunger to quantify the intangible impacts. Using our methodology, we expect that the quantification of the impact on hunger risk due to climate change and a better overall understanding would be possible.

We could interpret that a life lost due to undernourishment, which has not been considered in previous studies, is comparable to the positive impacts on human health shown in previous studies. For example an increase in GDP of $+0.5 \%$ from 2050 to 2100 was indicated by Tol (2013), although this study cannot be simply compared because the focus of the two studies is different. Tol (2013) considers the impact of medical expenditure, mortality, and diseases caused by extreme heat and cold, whereas the present study considers the impact due to undernourishment. Comparing the two studies, the decrease in death or disease associated with cold stress have resulted in a positive impact on the economy (Bosello et al. 2006; Tol 2013), but the health impacts considering the economic value of healthy lives lost through undernourishment, as shown in this study, reduce or even reverse the positive effect.

There were several limitations inherent in the present study;

- It did not consider the different access to medical services available in different socioeconomic conditions. In pessimistic socioeconomic conditions such as SSP3, some people might not have access to medical services and suffer from disease in low-income regions (Ebi 2013). It is assumed that medical services were accessed equally in all of the regions in this study. This assumption does not significantly change the results of the study because the medical expenditure of these regions is small, but this could be improved in future studies.

- The spatial distribution of the supply side was aggregated into 17 large regions. The spatial distribution of climate change impacts on food production might not change the main results of this study, but it might change the magnitude of the regional impacts. A regional downscaling could clarify the spatial distribution of the impacts and provide more useful information.

- The healthcare sector was aggregated with other service sectors to produce one service sector in the model. Separating out the healthcare sector would be a way of explicitly dealing with capital (e.g., labor) and intermediate inputs (e.g., pharmaceutical costs). This separation would require more information about the production structure of the medical services or products (e.g., capital and intermediate inputs needed for producing a unit of 
service or products) and such data at the global scale does not currently exist. Differences in productivity in the healthcare sector and in other service sectors might affect GDP loss, although further analysis is needed to determine whether and how the aggregation might change our results.

- Capital formation was partially considered in the model. When the demand for healthcare service increases, new capital might be allocated to the service sector or government might reduce their consumption and invest more money in the sector. The new capital allocation among different sectors was endogenously determined by the change in demand for goods and services. For example, construction of hospitals would reduce the capital allocation into other sectors (e.g., manufacturing). However, the reduction in government consumption was not considered. Incorporating such a mechanism requires a capital matrix that indicates how much of each commodity is allocated to investments in each sector, but this information was not available. Once the mechanism is introduced, investment (e.g., construction of a hospital) would occur over time and increase future production. This might bring about economic development or a decrease in health damage and healthcare services in the future, but such an analysis is not currently possible because of data unavailability.

- The current relationships between DALY and the number of deaths in seven regions of the world were applied to 17 regions for the future because of data limitations, although this might introduce biases. If DALY and the number of deaths by different countries, diseases, and risk factors were available, a further survey of the historical relationships in different countries and for different diseases would be appropriate.

- Some crop models used in the study do not include nitrogen stress as a result of our model selection, which was intended to take account of the uncertainty of the models as much as possible. Because the representation of nitrogen stress in the crop models is expected to cause more severe impacts (Rosenzweig et al. 2014), the selection of these models might have generated relatively optimistic results. Further studies should analyze the uncertainties related to the representation of nitrogen stress in crop models.

- The use of a discount rate when evaluating future healthy life years could lead to uncertainties. Because this study was based on DALY-evaluated future health years with a $3 \%$ discount rate, the discount rate was only partly considered. In reality, the discount rate might differ depending on the socioeconomic situation, but the difference was not taken into consideration.

Acknowledgments This work was supported by the Global Environment Research Fund of the Ministry of the Environment of Japan, Integrated Climate Assessment-Risks, Uncertainties and Society (ICA-RUS) (S10), and the Research on the development of an integrated assessment model incorporating global-scale climate change mitigation and adaptation (S-14-5).

Open Access This article is distributed under the terms of the Creative Commons Attribution 4.0 International License (http://creativecommons.org/licenses/by/4.0/), which permits unrestricted use, distribution, and reproduction in any medium, provided you give appropriate credit to the original author(s) and the source, provide a link to the Creative Commons license, and indicate if changes were made.

\section{References}

Bosello F, Roson R, Tol RSJ (2006) Economy-wide estimates of the implications of climate change. Human health. Ecol Econ 58:579-591 
Ciscar JC, Iglesias A, Feyen L, Szabo L, Van Regemorter D, Amelung B, Nicholls R, Watkiss P, Christensen OB, Dankers R, Garrote L, Goodess CM, Hunt A, Moreno A, Richards J, Soria A (2011) Physical and economic consequences of climate change in Europe. Proc Natl Acad Sci U S A 108:2678-2683

Cline WR (1992) The economics of global warming. Institute for International Economics, Washington, D.C.

Cropper ML, Hammitt JK, Robinson LA (2011) Valuing Mortality Risk Reductions: Progress and Challenges. National Bureau of Economic Research Working Paper Series No. 16971.

Ebi K (2013) Health in the new scenarios for climate change research. Inter J Environ Res Public Health 11:30-46

Ezzati M, Lopez A, Rodgers A, Murray C (2004) Comparative quantification of health risks: global and regional burden of disease due to selected major risk factors. WHO, Geneva, Switzerland

Fankhauser S (1995) Valuing climate change. The economics of the greenhouse. Earthscan, London

Fujimori S, Masui T, Matsuoka Y (2012) AIM/CGE [basic] manual. Discussion paper series. Center for Social and Environmental Systems Research, National Institute Environemntal Studies

Fujimori S, Kainuma M, Masui T, Hasegawa T, Dai H (2014) The effectiveness of energy service demand reduction: a scenario analysis of global climate change mitigation. Energy Policy 75:379-391

Hasegawa T, Fujimori S, Shin Y, Takahashi K, Masui T, Tanaka A (2014) Climate change impact and adaptation assessment on food consumption utilizing a new scenario framework. Environ Sci Technol 48:438-445

Hasegawa T, Fujimori S, Shin Y, Tanaka A, Takahashi K, Masui T (2015a) Consequence of climate mitigation on the risk of hunger. Environ Sci Technol 49:7245-7253

Hasegawa T, Fujimori S, Takahashi K, Masui T (2015b) Scenarios for the risk of hunger in the twenty-first century using shared socioeconomic pathways. Environ Res Lett 10:014010

IIASA (2012) Shared Socioeconomic Pathways (SSP) Database Version 0.9.3.

Ishida H, Kobayashi S, Kanae S, Hasegawa T, Fujimori S, Shin Y, Takahashi K, Masui T, Tanaka A, Honda Y (2014) Global-scale projection and its sensitivity analysis of the health burden attributable to childhood undernutrition under the latest scenario framework for climate change research. Environ Res Lett 9:064014

Lloyd SJ, Kovats RS, Chalabi Z (2011) Climate change, crop yields, and undernutrition: development of a model to quantify the impact of climate scenarios on child undernutrition. Environ Health Perspect 119:1817-1823

Lloyd S, Kovats S, Chalabi Z (2014) Undernutrition. In: Hales S, Kovats S, Lloyd S, Campbell-Lendrum D (eds) Quantitative risk assessment of the effects of climate change on selected causes of death, 2030s and 2050s. WHO, Swithland

Masutomi Y, Takahashi K, Harasawa H, Matsuoka Y (2009) Impact assessment of climate change on rice production in Asia in comprehensive consideration of process/parameter uncertainty in general circulation models. Agric Ecosyst Environ 131:281-291

Ministry of Health, Labour and Welfare of Japan (2015) Survey on the medical service 2013. Health Insurance Bureau, Beijing, China. Available online at http:/www.mhlw.go.jp/stf/seisakunitsuite/bunya/iryouhoken/ database/zenpan/iryoukyufu.html. Accessed 01 Oct 2015

National Health and Family Planning Commission of the People's Republic of China (2015) China Health Statistics Yearbook 2005, Tokyo, Japan. Available online at http://www.nhfpc.gov.cn/zwgkzt/tjnj/list.shtml. Accessed 01 Oct 2015

Nelson GC, Valin H, Sands RD, Havlík P, Ahammad H, Deryng D, Elliott J, Fujimori S, Hasegawa T, Heyhoe E, Kyle P, Von Lampe M, Lotze-Campen H, Mason d'Croz D, van Meijl H, van der Mensbrugghe D, Müller C, Popp A, Robertson R, Robinson S, Schmid E, Schmitz C, Tabeau A, Willenbockel D (2014) Climate change effects on agriculture: economic responses to biophysical shocks. Proc Natl Acad Sci 111:3274-3279

Nordhaus WD (1991) To slow or not to slow: the economics of the greenhouse effect. Econ J 101:920-937

OECD (2012) Mortality risk valuation in environment, health and transport policies, OECD Publishing. doi:10. 1787/10.1787/9789264130807-en/

Pearce DW (1978) The social incidence of environmental costs and benefits. In: O'Riordan T, Turner RK (eds) Progress in Resource Management and Environmental Planning. John Wiley \& Sons Ltd, Chichster, 2, p 63-87

Riahi K, Rao S, Krey V, Cho C, Chirkov V, Fischer G, Kindermann G, Nakicenovic N, Rafaj P (2011) RCP 8.5-a scenario of comparatively high greenhouse gas emissions. Clim Chang 109: 33-57

Rosenzweig C, Parry ML (1994) Potential impact of climate change on world food supply. Nature $367: 6$

Rosenzweig C, Elliott J, Deryng D, Ruane AC, Müller C, Arneth A, Boote KJ, Folberth C, Glotter M, Khabarov N, Neumann K, Piontek F, Pugh TAM, Schmid E, Stehfest E, Yang H, Jones JW (2014) Assessing agricultural risks of climate change in the 21 st century in a global gridded crop model intercomparison. Proc Natl Acad Sci 111:3268-3273

Smith KR, Woodward A, Campbell-Lendrum D, Chadee DD, Honda Y, Liu Q, Olwoch JM, Revich B, Sauerborn R (2014) Human health: impacts, adaptation, and co-benefits. In: Climate Change 2014: 
Impacts, Adaptation, and Vulnerability. Part A: Global and Sectoral Aspects. Contribution of Working Group II to the Fifth Assessment Report of the Intergovernmental Panel on Climate Change, Cambridge University Press, Cambridge, United Kingdom and New York, NY, USA.

Tol RSJ (1996) The damage costs of climate change towards a dynamic representation. Ecol Econ 19:67-90

Tol RJ (2013) The economic impact of climate change in the 20th and 21st centuries. Clim Chang 117:795-808 van Vuuren DP, Stehfest E, Elzen MGJ, Kram T, Vliet J, Deetman S, Isaac M, Klein Goldewijk K, Hof A, Mendoza Beltran A, Oostenrijk R, Ruijven B (2011) RCP2.6: exploring the possibility to keep global mean temperature increase below $2{ }^{\circ} \mathrm{C}$. Clim Chang 109:95-116

Watkiss P, Hunt A (2012) Projection of economic impacts of climate change in sectors of europe based on bottom up analysis: human health. Clim Chang 112:101-126

WHO (2014a) Global Health Estimates. Available online at http://who.int/healthinfo/global_burden_disease/en/. Accessed 01 March 2015

WHO (2014b) Global Health Observatory (GHO). Available online at http://who.int/gho/mortality_burden disease/life_tables/en/. Accessed 01 March 2015 